\title{
Filamentous Fungi Count
}

National Cancer Institute

\section{Source}

National Cancer Institute. Filamentous Fungi Count. NCI Thesaurus. Code C147343.

The determination of the amount of filamentous fungus present in a sample. 